\title{
Predictive Factors for Postoperative Visual Recovery in Surgically Treated Suprasellar Meningioma: A Retrospective Analysis
}

\author{
MOHAMMED F.A. ALI, M.D.*; HIDER AL-SHAMI, M.R.C.S., E.F.N.S.** and \\ MOHAMED F. ALSAWY, M.D.* \\ The Departments of Neurosurgery, Faculty of Medicine, Cairo University* and Bank Al-Ahly Hospital**
}

\begin{abstract}
Background: Post-operative visual outcome in surgically treated suprasellar meningiomas is a great concern for surgeon, patient and of course for the health system. Certain reports were published before questioning about the aim of treating such tumors in which visual recovery cannot be guaranteed. It is important to classify the possible factors that may predict the prognosis thereafter.
\end{abstract}

Aim of Study: Assessment of the visual function perioperatively and to delineate the factors of visual recovery in surgically treated suprasellar meningioma.

Patients and Methods: This was a retrospective analysis of 24 patients who were operated for suprasellar meningioma in Kasr Al-Ainy University Hospital from January 2018 to July 2020. The following predictive factors were tested: Age, duration of symptoms, pre-operative visual function damage, and radiological criteria of the tumor.

Results: An overall improvement in visual function was seen in $14 / 24$ patients $(58.3 \%)$ in our study. The mean and standard deviation of symptoms' duration in months were 12.36 \pm 5.11 (3-23 months). Gross total resection was achieved in 19 cases $(79.1 \%)$. Gross total resection achieved improvement of overall visual function in $73.7 \%$ of cases with statistically significant difference versus subtotal resection ( $p$-value $=0.03$ ). It has been found that duration of symptoms (less than 12 months), mild pre-operative visual symptoms, tumor size less than $3 \mathrm{~cm}$, absence of optic nerve extension and gross total resection are related to post-operative improvement in visual outcome.

Conclusion: Visual recovery of surgically treated suprasellar meningiomas is greatly dependent on duration of symptoms, pre-operative visual status, tumor size, adherence to strategic neurovascular structures and gross total resection.

Key Words: Suprasellar meningioma - Visual field - Visual acuity-Optic nerve - Chasm.

Correspondence to: Dr. Mohammed F.A. Ali, The Department of Neurosurgery, Faculty of Medicine, Cairo University

\section{Introduction}

SUPRASELLAR meningioma constitutes 5-10\% of all intracranial meningiomas. Meningiomas which target the visual pathway are those originating from basal meninges of planum sphenoidale, chismatic sulcus, diaphragma sellae and tuberculum sellae [1]. The growth of these types of meningiomas are usually within the subchiasmatic vicinity which may cause displacement of optic nerve, chiasm and optic tracts especially in large tumors. This displacement can lead to elevation, dislocation or compression of such highly sensitive structures $[2,3]$. Accordingly, visual acuity and field may deteriorate at time of compression [3-6]. Surgical treatment offers decompression of mass, decompression of opticoochiasmatic system, arrest of visual deterioration and hopefully, visual acuity improvement [7-9]. Gross or subtotal resection may offer post-operative improvement on visual function as stated by some series in the literature. However, other series found no change at short term followup [10,11]. Previous literatures tested certain predictive variables to conclude dependency of visual recovery $[4-6,12,13]$

The aim of the study is to assess the visual function perioperatively and to delineate the factors of visual recovery.

\section{Material and Methods}

\section{Study design and recruitment:}

This was a retrospective analysis of patients who were operated for suprasellar meningioma in Kasr Al-Ainy University Hospital from January 2018 to July 2020 . Ethical approval was obtained from our ethical committee prior to study conduction. There were 43 patients who were diagnosed with suprasellar meningioma confirmed by Mag- 
netic Resonance Imaging (MRI) and Computed Tomography (CT) scans. Inclusion criteria included Meningiomas with optochiasmatic system compromise which were operated by transcranial approach and age from 18 to 80 years old. Exclusion criteria included incomplete medical data for data retrieval, histopathological diagnoses other than meningioma grade I, meningiomas operated via endoscopic approach, tumors operated by incisional biopsy, cases with post-operative hemorrhage in surgical bed, recurrent cases and concomitant local visual affection like cataract or glaucoma. Twenty-four medical records were selected out of 43 Fig. (1).

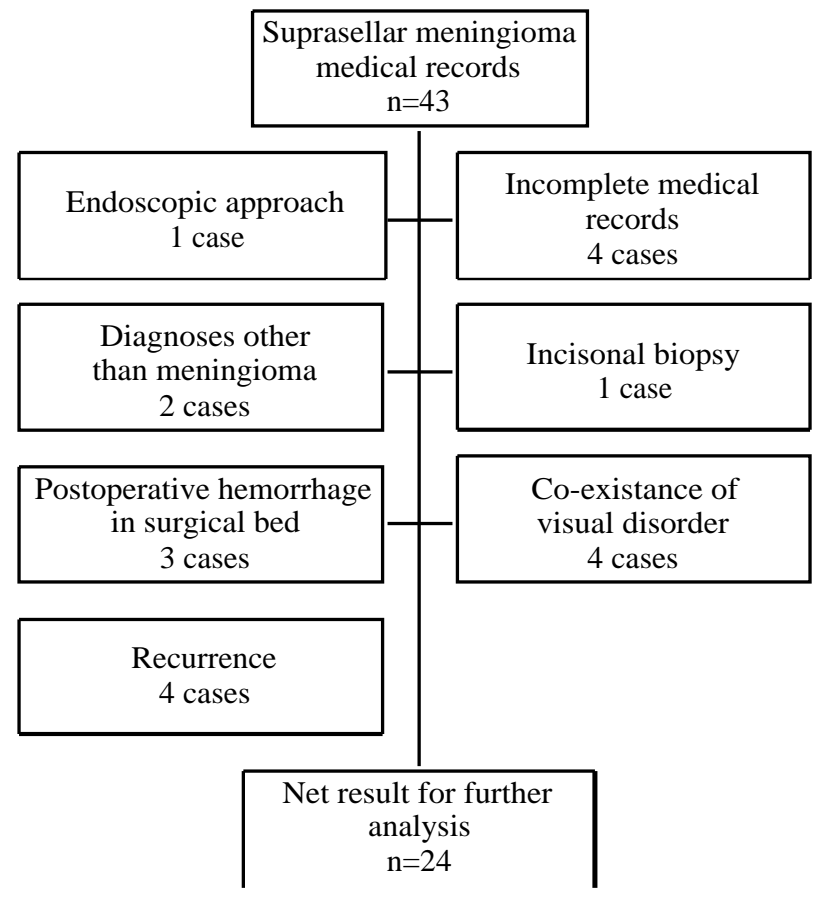

Fig. (1): Flow chart of case selection in our study.

\section{Study parameters and predictive factors:}

The following parameters were recorded; history taking and clinical examination, radiological data of tumor site and size (maximum diameter in $\mathrm{mm}$ ), visual field and visual acuity before and 14 days post-surgery. The following predictive factors were tested: Age, duration of symptoms, preoperative visual function damage, and size of the tumor. During statistical evaluation, any change in visual field or acuity post-operatively was ranked as either; deteriorated, improved or unchanged in the overall-visual function.

\section{Surgical approaches:}

Different surgical approaches were used. Pterional approach was used in 14 patients; unilateral subfrontal craniotomy was used in 6 patients while bifrontal craniotomy was used in 4 patients.

\section{Follow-up:}

Early brain CT without contrast is mandatory prior to discharge to exclude presence of hematoma. Visual function was assessed at 14 th day and 3months post-operatively. At 3 months interval, MRI brain with contrast was requested for every patient to assess residual part of tumor.

\section{Statistical analysis:}

Statistical analysis was performed using SPSS software. Univariate analysis of clinical and surgical parameters was performed using Fisher's exact test. Statistical significance was accepted at $p$ values less than 0.05 .

\section{Results}

\section{Patients' criteria:}

The mean and standard deviation of age is 50.6 years \pm 2.18 with range (23-77 years). The patients were sub classified according to the median age (52 years) as shown in (Table 1). It has been found that younger patients tend to have visual improvement post-operatively $(p$-value $=0.005)$. Male patients' constituted $37.5 \%$ of our study patients $(9 / 24$ patients) as shown in (Table 1).

\section{Perioperative visual assessment:}

Pre-operative decline in visual function was not seen in almost all patients. An overall improvement in visual function was seen in 14/24 patients (58.3\%) in our study. The mean and standard deviation of symptoms' duration in months were $12.36 \pm 5.11$ (3-23 months). Patients with long lasting duration of visual complain (>12 months) tend to have neither improvement nor deterioration in overall visual function $(p$-value $=0.0172)$. Visual acuity and visual field defects were estimated by estimating number of affected eyes. Forty-eight eyes' visual assessment report showed severe visual affecting in 23 eyes (NPL, HM) while partial affection was seen in 20 eyes. We used chi-square $t$-test to compare the improvement in overall visual outcome between partial and severely affected eyes. It has been found that partially affected eyes are more prone to post-operative improvement in short term follow-up ( $p$-value $<0.001$ ). There were 31 eyes with field deficits pre-operatively, only 12 eyes showed improvement thereafter with no statistically significant difference between partial and severely affected eyes ( $p$-value $=0.077)$.

\section{Radiological criteria:}

The locations of Meningiomas are illustrated in Fig. (2). Tumors with maximum diameter less than $3 \mathrm{~cm}$ showed $100 \%$ improvement in overall visual function $(p$-value $=0.0042)$ while 10 patients 
out of 16 patients with tumor size larger than $3 \mathrm{~cm}$ showed no improvement. However, this was of no statistically significant difference $(p$-value $=0.891)$.

Arterial encasement was seen in 16 patients. Chi-square $t$-test was done to compare the overall visual improvement in no-encasement group (8 patients) versus arterial encasement group (16 patients). It has been found that presence of either unilateral or bilateral encasement of ICA is a factor for non improvement in overall visual function ( $p$ value $=0.023$ ). Retrosellar extension was seen mainly in diaphragma sellae and tuberculum sellae meningiomata ( 4 patients and 3 patients) respectively. Optic nerve extension was seen in 6 patients ( 3 in chismatic sulcus, 2 in tuberculum sellae meningioma and one case of planum sphenoidale). It has been found that decompression of optic nerve part was not significantly improving the overall visual outcome $(p$-value $=1.00)$.

Calcifications were detected by pre-operative CT scan in 7 patients with no statistically significant impact $(p$-value $=0.12)($ Table 1$)$, in contrast, T2 hyperintensity was found to be statistically different in post-operative visual outcome $(p$-value $=0.0014)$.

\section{Resectability:}

Gross total resection was achieved in 19 cases $(79.1 \%)$ as shown in (Table 1). It has been found that gross total resection achieved improvement of overall visual function in $73.7 \%$ of cases with statistically significant difference versus subtotal resection $(p$-value $=0.03)$.

\section{Regression analysis:}

A logistic regression analysis was done to express the prognostic factors related to overall visual function improvement. The following factors were plotted in (Table 2). It has been found that duration of symptoms (less than 12 months), mild preoperative visual symptoms, tumor size less than $3 \mathrm{~cm}$, absence of optic nerve extension and gross total resection are related to post-operative improvement in visual outcome.

Table (1): Clinical and radiological criteria.

\begin{tabular}{|c|c|c|c|c|}
\hline \multirow{2}{*}{ Item } & \multirow{2}{*}{$\mathrm{N}$} & \multicolumn{2}{|c|}{ Overall visual function } & \multirow{2}{*}{$\begin{array}{c}p- \\
\text { value }\end{array}$} \\
\hline & & Improvement & Unchanged & \\
\hline $\begin{array}{l}\text { Patients' demographic data: } \\
\text { - Age }<52 \mathrm{y} \\
\text { - Age }>52 \mathrm{y} \\
\text { - Sex (male) }\end{array}$ & $\begin{array}{l}14(58.33 \%) \\
10(41.6 \%) \\
9 \quad(37.5 \%)\end{array}$ & $\begin{array}{l}11 \\
2 \\
4\end{array}$ & $\begin{array}{l}3 \\
8 \\
5\end{array}$ & $\begin{array}{l}0.005^{*} \\
0.119\end{array}$ \\
\hline $\begin{array}{l}\text { Clinical examination: } \\
\text { - Duration of symptoms }\end{array}$ & $\begin{array}{l}<12 \mathrm{~m}: 11 \\
>12 \mathrm{~m}: 13\end{array}$ & $\begin{array}{l}7 \\
2\end{array}$ & $\begin{array}{l}4 \\
11\end{array}$ & $0.0172 *$ \\
\hline - Visual acuity (48 eyes) & $\begin{array}{l}\text { Normal:5 } \\
\text { Partial:20 } \\
\text { Sever:23 }\end{array}$ & $\begin{array}{l}0 \\
18 \\
10\end{array}$ & $\begin{array}{l}5 \\
2 \\
13\end{array}$ & $<0.001 *$ \\
\hline - Visual field defect (48 eyes) & $\begin{array}{l}\text { Positive:31 } \\
\text { Negative: } 17\end{array}$ & $\begin{array}{l}12 \\
-\end{array}$ & $\begin{array}{l}19 \\
17\end{array}$ & 0.077 \\
\hline $\begin{array}{l}\text { Radiological criteria: } \\
\text { - Tumor size }(<3 \mathrm{~cm}) \\
\text { - Tumor size }\end{array}$ & $\begin{array}{l}<3: 8 \\
>3: 16\end{array}$ & $\begin{array}{l}8 \\
10\end{array}$ & $\begin{array}{l}0 \\
6\end{array}$ & $0.0042 *$ \\
\hline $\begin{array}{l}\text { Extent: } \\
\text { - Arterial encasement }\end{array}$ & $\begin{array}{l}\text { Normal: } 8 \\
\text { ICA (one side): } 8 \\
\text { ICA (both sides):8 } \\
\text { ACA } 2\end{array}$ & $\begin{array}{l}7 \\
4 \\
2 \\
2\end{array}$ & $\begin{array}{l}1 \\
4 \\
6 \\
0\end{array}$ & $0.023 *$ \\
\hline $\begin{array}{l}\text { - Retrosellar extension } \\
\text { - Optic nerve extension }\end{array}$ & $\begin{array}{l}7 \\
6\end{array}$ & $\begin{array}{l}6 \\
3\end{array}$ & $\begin{array}{l}1 \\
3\end{array}$ & $\begin{array}{l}0.01^{*} \\
1.000\end{array}$ \\
\hline $\begin{array}{l}\text { Nature: } \\
\text { - Calcification } \\
\text { - T2 hyperintensity }\end{array}$ & $\begin{array}{l}7 \\
12\end{array}$ & $\begin{array}{l}5 \\
10\end{array}$ & $\begin{array}{l}2 \\
3\end{array}$ & $\begin{array}{l}0.12 \\
0.0014 *\end{array}$ \\
\hline $\begin{array}{l}\text { Resectability: } \\
\text { - Gross total resection } \\
\text { - Subtotal resection }\end{array}$ & $\begin{array}{l}19 \\
5\end{array}$ & $\begin{array}{l}14 \\
1\end{array}$ & $\begin{array}{l}5 \\
4\end{array}$ & $0.0383 *$ \\
\hline
\end{tabular}


Table (2): Regression analysis.

\begin{tabular}{llll}
\hline Item & OR & $95 \%$ CI & $p$-value \\
\hline Duration of symptoms & 0.89 & $0.82-0.96$ & $0.042^{*}$ \\
Age <50 & 1.01 & $0.94-1.08$ & 0.066 \\
Partial affection of visual acuity (prop.) & 1.84 & $0.44-3.24$ & $0.001 *$ \\
Visual field deficit (pre-op.) & 0.97 & $0.79-1.15$ & $0.011^{*}$ \\
Size <3cm & 1.1 & $0.84-1.36$ & $0.001^{*}$ \\
Absence of arterial encasement & 0.96 & $0.15-5.76$ & 0.88 \\
Absence of retrosellar extension & 0.7 & $0.15-1.25$ & 0.1 \\
Absence of optic nerve extension & 0.96 & $0.22-1.7$ & 0.45 \\
T2 hyperintensity & 0.66 & $0.23-1.09$ & 0.761 \\
Gross total resection & 0.98 & $0.27-1.69$ & $0.005^{*}$ \\
\hline
\end{tabular}

\section{Case presentation:}

A 48 years old female patient was admitted to Neurosurgery Department due to headache and blurring of vision for about 6 months. She had no history of diabetes or hypertension and did not take any medications for any chronic diseases. Neurological examination was unremarkable except decreased visual acuity on left eye more than right eye $($ Rt eye $=6 / 60$, Lt eye $=$ Hand movement $)$ with left hemianopia. Initial CT scan without contrast showed a suprasellar mass with $3 * 4 * 3.5 \mathrm{~cm}$ Fig. (3).

Further imaging of this lesion with contrast enhanced MRI brain showed homogenously enhanced lesion (tuberculum sellae meningioma) with complete encasement of left ICA and partial encasement of right ICA Fig. (4). Axial T2 weighted images showed no hyperintensity with minimal surrounding brain edema Fig. (5).

A pterional approach and craniotomy was implemented to target the lesion with meticulous dissection of the neurovascular bundle and remov- ing the tumor totally. Her post-operative course was unremarkable. At follow-up, she recorded improvement in visual acuity $(6 / 60,6 / 60)$ with disappearance of field defect (at 30 days followup).

Bar chart distribution of histopathological diagnoses in our study

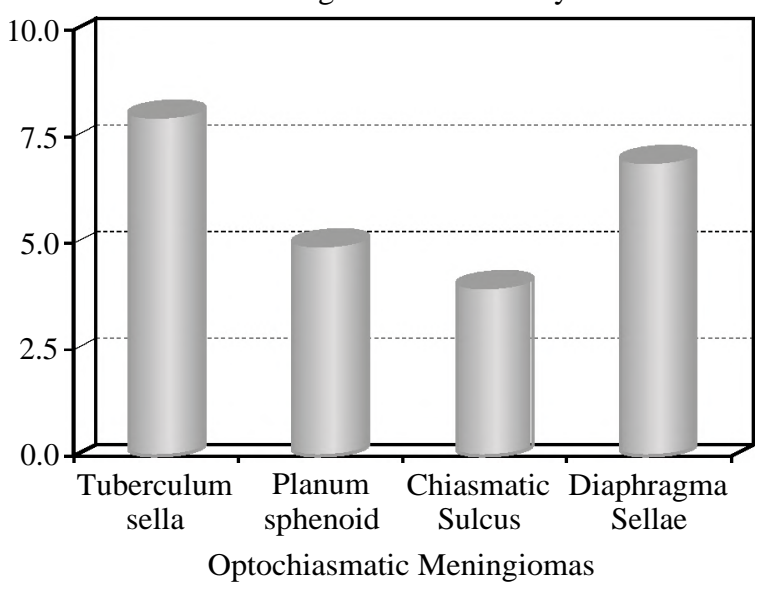

Fig. (2): Bar chart of locations of the meningiomas in our study.

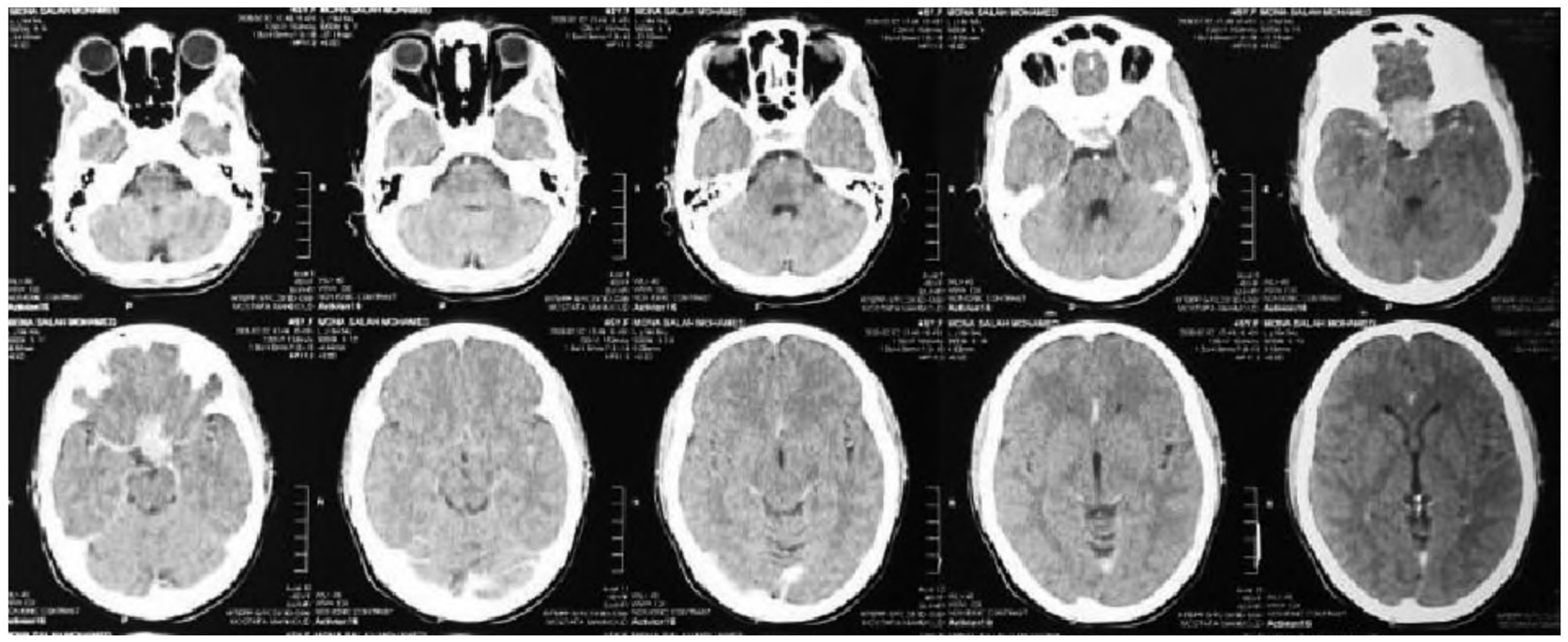

Fig. (3): Non-contrast CT scan of the brain showed sellar lesion with encroachment on both anterior clinoid processes. 


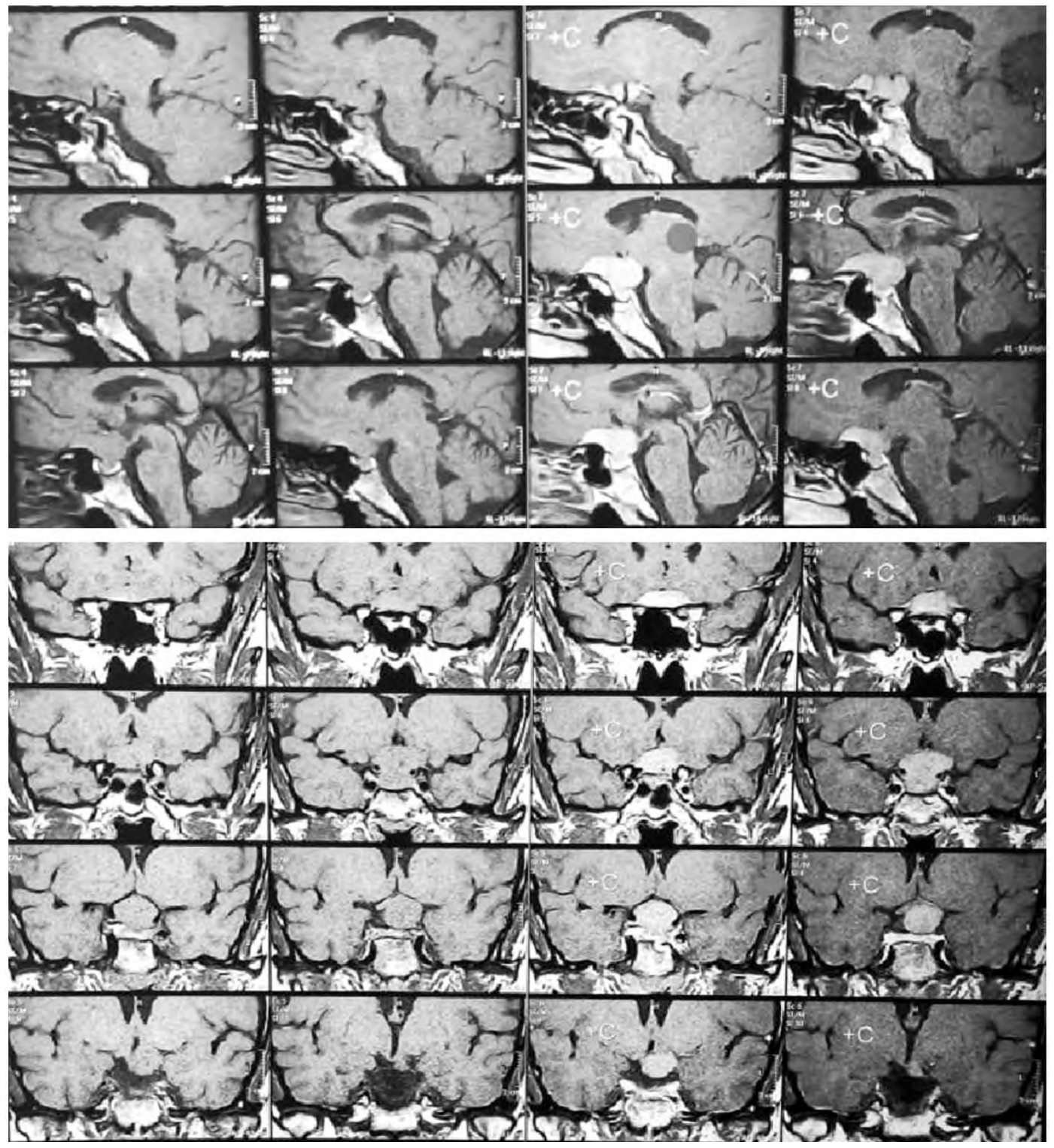

Fig. (4): Above, MRI brain with contrast (sagittal view showed suprasellar mass with underlying normal pituitary gland. Below, coronal images of the same lesion with partial encasement of ICA on right side and complete encasement on the left side.

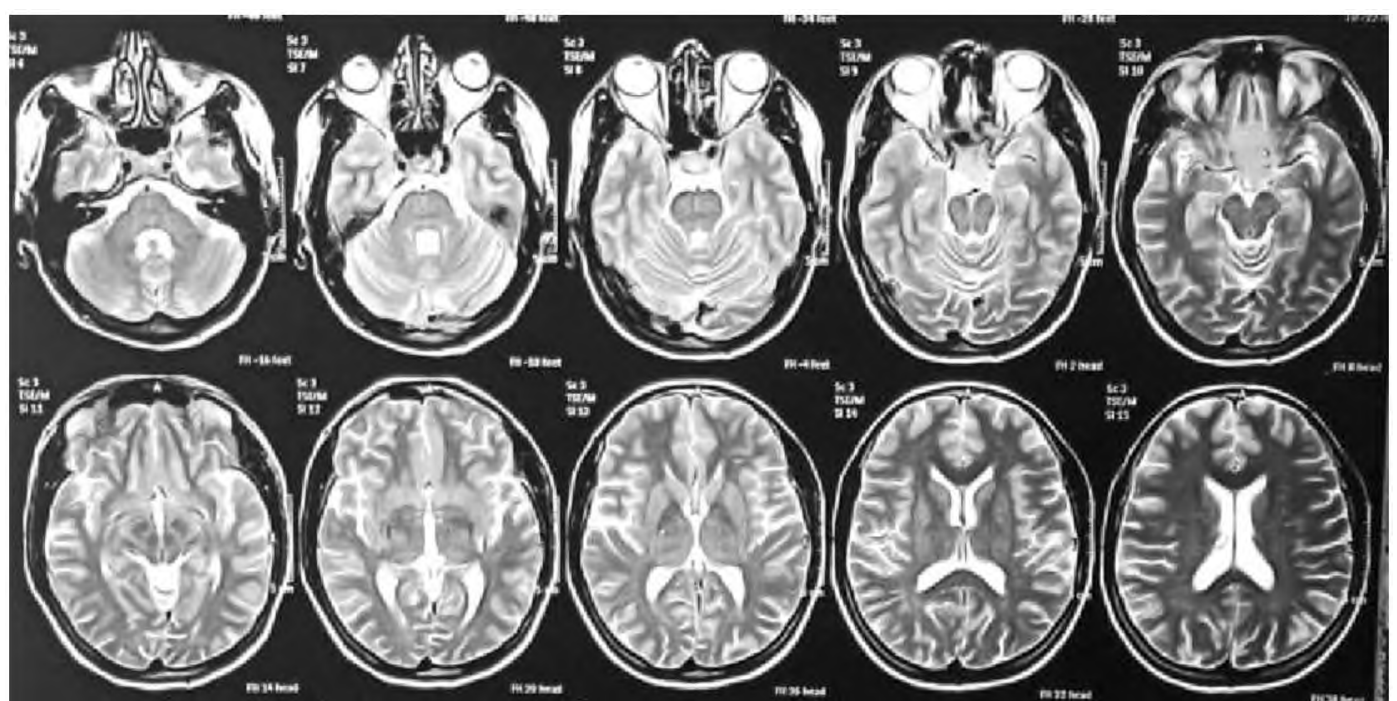

Fig. (5): Axial T2 weighted images showed no T2 hyperintensity of the targeted lesion with minimal surrounding brain edema. 


\section{Discussion}

Suprasellar meningiomas are presented mainly with visual symptoms for longer duration prior to definitive diagnosis [1,14]. Indeed, encasement of adjacent arterial structure (ICA or ACA) may complicate tumor removal $[\mathbf{1 5 , 1 6 ]}$. Therefore, gross total resection mandates meticulous dissection of neurovascular structure [3-5,13].

In this series, twentyfour patients with suprasellar meningioma were operated over 2 years. The mean follow-up duration was 19 months. Finally 14 patients $(58.3 \%)$ showed improvement in visual function post-operatively whereas visual outcome was unchanged in $10(41.6 \%)$ patients. Visual deterioration was not recorded during follow-up.

In this retrospective analysis, the predictive factors that hold a great statistically significance were symptoms' duration, mild pre-operative visual affection, tumors less than $3 \mathrm{~cm}$, absence of arterial encasement and finally gross total resection $[\mathbf{4 , 6 , 9}$, 11-13].

Patients with shortest duration of visual complaint were found to have better post-operative outcome when removing the compressing mass (regardless of its size) $[\mathbf{3 , 5 , 6 ]}$. This will offer a great opportunity to opticochiasmatic apparatus to regain its normal function. This correlation was mentioned previously in many series $[\mathbf{1 0 , 1 4 , 1 7 ]}$.

Tumors with maximum diameter less than $3 \mathrm{~cm}$ were found to be correlated with better postoperative visual outcome $[2,4,9]$. This may be related to its mild compression on chiasm and/or optic nerve at beginning [7]. Indeed, such tumor sizes do not require heavy or even lengthy microsurgical dissection as seen in large tumors especially with arterial encasement. The minimal manipulations of the neurovascular structures together with the initial mild affection may account for the good outcome in this group of patients as mentioned previously in many literatures $[\mathbf{1 1}, \mathbf{1 5 , 1 6 , 1 8}]$

Tumors with $\mathrm{T} 2$ hyperintensity reflect great possibility of soft nature [19], which in turn increases the possibility of a relatively easier tumor excision without the need of prolonged manipulations of the tumor against the surrounding sensitive neural structures of the optic apparatus. Consequently this radiological feature may be related to a good possibility of having good overall visual outcome post-operatively as deemed to have a statistical significance in the univariate analysis. However, regression analysis showed insignificant correlation $(p$-value $=0.761)$.
In our study, patients' age was not found as a prognostic factor for visual function recovery. However, several reports showed the reverse, being less than the age of 50 years old is a prognostic factor for visual recovery $[\mathbf{5 , 6 , 1 1 , 1 3 ]}$. We might explain this with the relevant delay of presentations in our patients.

Optic nerve extension is a common finding in tuberculum sellae meningioma followed by chiasmatic sulcus lesions [20,21]. Deroofing of the optic nerve either by extradural or intradural anterior clinoidectomy offers a great relief to the nerve. Routine optic nerve decompression for tuberculum sellae and diaphragma sellae meningioma is mentioned previously in many literatures [20-23]. Optic nerve extension was reported in our study in 6 patients. Deroofing of optic nerve and removing of tumor part in the optic canal was achieved in almost all cases [22]. Visual outcome was not correlated to removing of compressing tumor part in optic canal. Fifty percent of patients with optic nerve extension showed improvement in overall visual function post-operatively, indeed, it was not of regarded as prognostic factor during analysis.

Gross total resection was achieved in 19/24 (79.1\%) of cases. Gross total resection is a common prognostic factor for visual recovery in many literatures $[\mathbf{5 , 6 , 1 2 , 2 4 , 2 5}]$. This can be emphasized as Simpson GII resection provided the maximum decompression effect to optico-chiasmatic apparatus [24]. Residual tumors tend to develop postoperative edematous sequlae which increase the compressive effect to the double compared to preoperative condition due to repeated manipulations of optic nerve and chiasm $[2,6,13]$.

\section{Conclusion:}

Visual recovery of surgically treated suprasellar meningiomas is greatly dependent on duration of symptoms, pre-operative visual status, tumor size, adherence to strategic neurovascular structures and gross total resection.

\section{Conflict of interest:}

Non to declare.

\section{References}

1- CHANDLER W.F.: Management of Suprasellar Meningiomas. Journal of Neuro-Ophthalmology, 23 (1): 1-2. doi: 10.1097/00041327-200303000-00001, 2003.

2- MARINIELLO G., De DIVITIIS O., BONAVOLONTÀ G. and MAIURI F.: Surgical unroofing of the optic canal and visual outcome in basal meningiomas. Acta Neurochirurgica, 155 (1): 77-84. doi: 10.1007/s00701-0121485-z, 2013. 
3- TAHA A.N.M., ERKMEN K., DUNN I.F., PRAVDENKOVA S. and AL-MEFTY O.: Meningiomas involving the optic canal: Pattern of involvement and implications for surgical technique. Neurosurgical Focus, 30 (5): 1-8. doi: 10.3171/2011.2.FOCUS1118, 2011.

4- CHICANI C.F. and MILLER N.R.: Visual outcome in surgically treated suprasellar meningiomas. Journal of Neuro-Ophthalmology, 23 (1): 3-10. doi: .1097/00041327200303000-00002, 2003.

5- GALAL A., FAISAL A., AL-WERDANY M., EL SHEHABY A., LOTFY T. and MOHARRAM H.: Determinants of post-operative visual recovery in suprasellar meningiomas. Acta Neurochirurgica, 152 (1): 69-77. doi: 10.1007/ s00701-009-0492-1, 2010.

6- GRKOVIC D. and DAVIDOVIC S.: Prognostic Factors for Post-operative Visual Outcome in Surgically Treated Suprasellar Meningiomas. Medicinski pregled, 69 (5-6): 146-52. doi:10.2298/mpns1606146g, 2016.

7- BASSIOUNI H., ASGARI S. and STOLKE D.: Tuberculum sellae meningiomas: Functional outcome in a consecutive series treated microsurgically. Surgical Neurology, 66 (1): 37-44. doi: 10.1016/j.surneu.2005.11.059, 2006.

8- KWANCHAROEN R., BLITZ A.M., TAVARES F., CATUREGLI P., GALLIA G.L. and SALVATORI R.: Clinical features of sellar and suprasellar meningiomas. Pituitary, 17 (4): 342-8. doi:10.1007/s11102-013-0507-z, 2014.

9- LU Z.F., CHENG X.B., ZHAO Y.G. and SHI B.Z.: Twentynine cases of resection of suprasellar meningioma through small bone window: An interhemispheric approach. Wspolczesna Onkologia, 17 (6): 525-9. doi: 10.5114/ wo.2013.38913, 2013

10- WANG C.W., LI Y.Y., ZHU S.G., et al.: Surgical management and evaluation of prognostic factors influencing post-operative visual outcome of suprasellar meningiomas. World Neurosurgery, 75 (2): 294-302. doi: 10.1016/ j.wneu.2010.08.021, 2011.

11- AUI-AREE N., PHRUANCHROEN C., OEARSAKUL T., HIRUNPAT S. and SANGTHONG R.: Three years experience of suprasellar tumors in neuro-ophthalmology clinic. Journal of the Medical Association of Thailand, 93 (7): 818-23, 2010.

12- RASSI M.S., PRASAD S., CAN A., PRAVDENKOVA S., ALMEFTY R. and AL-MEFTY O.: Prognostic factors in the surgical treatment of intracanalicular primary optic nerve sheath meningiomas. Journal of Neurosurgery, 131 (2): 481-8. doi: 10.3171/2018.4.JNS173080, 2019.

13- SURI A., NARANG K.S., SHARMA B.S. and MAHAPATRA A.K.: Visual outcome after surgery in patients with suprasellar tumors and pre-operative blindness. Journal of Neurosurgery, 108 (1): 19-25. doi: 10.3171/ JNS/2008/108/01/0019, 2008

14- JALLU A., KANAAN I., RAHM B. and SIQUEIRA E.: Suprasellar meningioma and blindness: A unique experience in Saudi Arabia. Surgical neurology, 45 (4): 320-3 doi: 10.1016/0090-3019(95)00456-4, 1996.
15- ANDREWS B.T. and WILSON C.B.: Supresellar meningiomas: The effect of tumor location on post-operative visual outcome. Journal of Neurosurgery, 69 (4): 523-8. doi: 10.3171/jns.1988.69.4.0523, 1988.

16- PUCHNER M.J.A., FISCHER-LAMPSATIS R.C.M., HERRMANN H.D. and FRECKMANN N.: Suprasellar meningiomas: Neurological and visual outcome at long term follow-up in a homogeneous series of patients treated microsurgically. Acta Neurochirurgica, 140 (12): 12311238. doi: 10.1007/s007010050243, 1998.

17- NOZAKI K., KIKUTA K.I., TAKAGI Y., MINEHARU Y., TAKAHASHI J.A. and HASHIMOTO N.: Effect of early optic canal unroofing on the outcome of visual functions in surgery for meningiomas of the tuberculum sellae and planum sphenoidale. Neurosurgery, 62 (4): 839-44. doi: 10.1227/01.neu.0000318169.75095.cb, 2008.

18-MENENGIOM S.Y. and ETKISI P.B.: Early Post Operative Visual Outcome in Microsurgically Treated Suprasellar Meningiomas Predict Long-Term Visual Outcome Mikrocerrahi Yöntem ile Ç > kar > lm > fl Olgular > nda Erken Postoperatif. Turkish Neurosurgery, 18 (4): 3806, 2008 .

19- CUNLIFFE C.H., FISCHER I., MONOKY D., et al.: Intracranial lesions mimicking neoplasms. Archives of Pathology and Laboratory Medicine, 133 (1): 101-23. doi: 10.1043/1543-2165-133.1.101, 2009.

20- PALANI A., PANIGRAHI M.K. and PUROHIT A.K.: Tuberculum sellae meningiomas: A series of 41 cases; surgical and ophthalmological outcomes with proposal of a new prognostic scoring system. Journal of Neurosciences in Rural Practice, 03 (03): 286-93. doi: 10.4103/ 0976-3147.102608, 2012

21- ESTEVÃO I.A., CAMPOREZE B., MATRICARDI G., et al.: Tuberculum sellae meningioma: Is there an ideal approach? Medical Express, 4 (4): 1-7. doi: 10.5935/ medicalexpress.2017.04.03, 2017.

22- OTANI N., MUROI C., YANO H., KHAN N., PANGALU A. and YONEKAWA Y.: Surgical management of tuberculum sellae meningioma: Role of selective extradural anterior clinoidectomy. British Journal of Neurosurgery, 20 (3): 129-38. doi:10.1080/02688690600776747, 2006.

23- DOGAN I., UCER M. and BA SKAYA M.K.: Microsurgical Resection of Tuberculum Sellae Meningioma via Pterional Craniotomy with Extradural Anterior Clinoidectomy and Optic Unroofing. Journal of Neurological Surgery, Part B: Skull Base, 79 (2): 1620254. doi: 10.1055/ s-0037-1620254, 2018.

24- SEKHAR L.N., RAMANATHAN D. and FERREIRA M.: Post-operative visual outcome of suprasellar meningiomas. World Neurosurgery, 75 (2): 219-21. doi: 10.1016/ j.wneu.2010.10.015, 2011

25- GRKOVIC' D., BEDOV T., CANADANOVIC' V., BABIC N. and BARISIC' S.: Post-operative visual recovery following surgical treatment of suprasellar meningiomas. Medicinski pregled, 65 (7-8): 309-14. doi: 10.2298/ MPNS 1208309G, 2012 


\section{العوامل المؤثرة فى تحسن الإبصار لمرضى الآورام السحائية ما فوق السرج بعد إستئصالها جراسيا:}

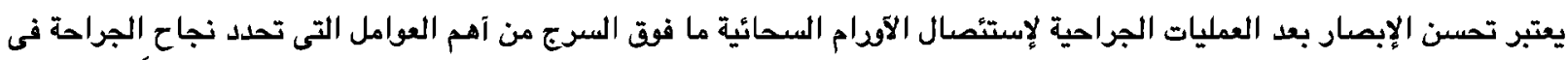

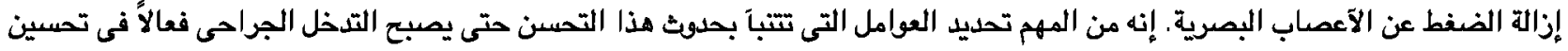
جودة الحياة للمرضى الذين يعانون من هذه الآمدام.

لقد تمت هذه الدراسة على ع مريض يعانون من آودام سحائية فوق السرج والذين قد خضعوا لعمليات جراحية لإستئصال هذه الآقدام

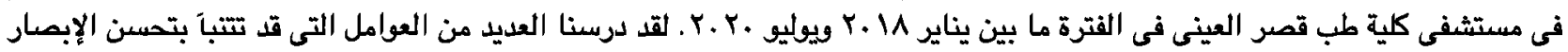

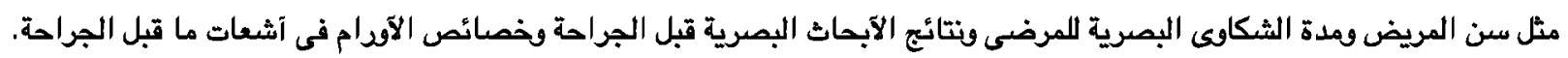

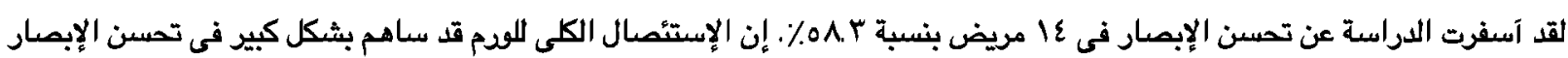

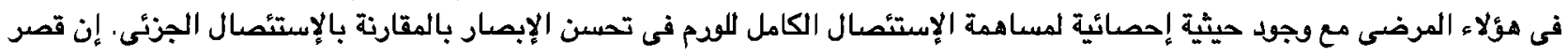

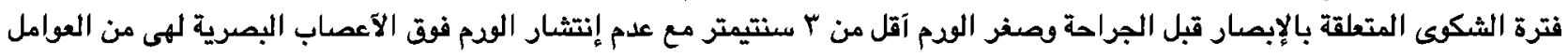

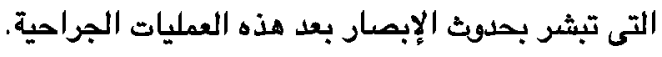

